
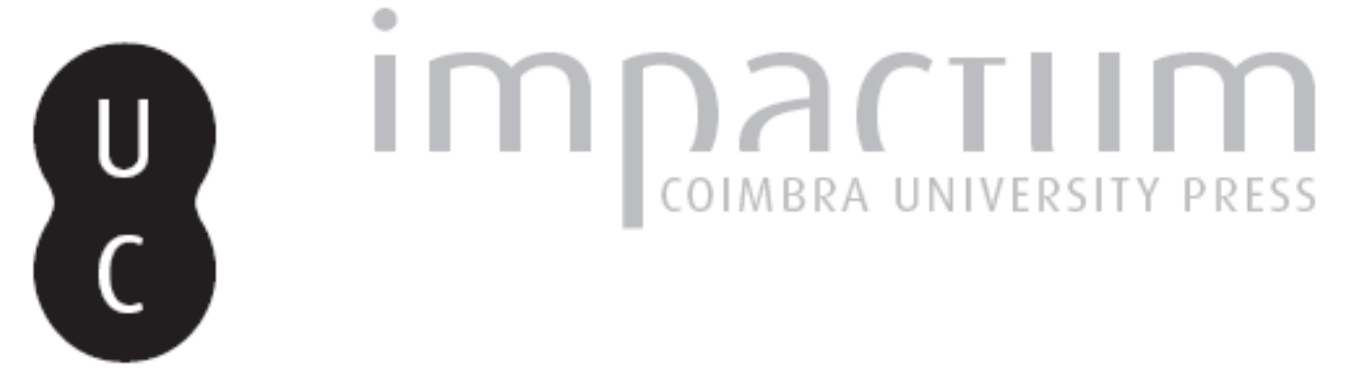

\title{
Avaliação espacio-temporal das precipitações extremas e seus impactos no meio urbano: um caso brasileiro
}

Autor(es): $\quad$ Castellano, Marina Sória; Nunes, Lucí Hidalgo

Publicado por: Associação Portuguesa de Riscos, Prevenção e Segurança

URL persistente:

URI:http://hdl.handle.net/10316.2/36093

DOI:

DOI:http://dx.doi.org/10.14195/1647-7723_17_4

Accessed : $\quad$ 26-Apr-2023 04:26:14

A navegação consulta e descarregamento dos títulos inseridos nas Bibliotecas Digitais UC Digitalis, UC Pombalina e UC Impactum, pressupõem a aceitação plena e sem reservas dos Termos e Condições de Uso destas Bibliotecas Digitais, disponíveis em https://digitalis.uc.pt/pt-pt/termos.

Conforme exposto nos referidos Termos e Condições de Uso, o descarregamento de títulos de acesso restrito requer uma licença válida de autorização devendo o utilizador aceder ao(s) documento(s) a partir de um endereço de IP da instituição detentora da supramencionada licença.

Ao utilizador é apenas permitido o descarregamento para uso pessoal, pelo que o emprego do(s) título(s) descarregado(s) para outro fim, designadamente comercial, carece de autorização do respetivo autor ou editor da obra.

Na medida em que todas as obras da UC Digitalis se encontram protegidas pelo Código do Direito de Autor e Direitos Conexos e demais legislação aplicável, toda a cópia, parcial ou total, deste documento, nos casos em que é legalmente admitida, deverá conter ou fazer-se acompanhar por este aviso.

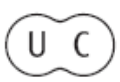




\section{territorium}

Riscos, Sociedade(s) e Segurança

Revista da Associação Portuguesa de Riscos, Prevenção e Segurança 2010 

BRASILEIRO $^{1 *}$

\author{
Marina Sória Castellano \\ Instituto de Geociências - Universidade Estadual de Campinas (UNICAMP) \\ ninasoria@gmail.com \\ Lucí Hidalgo Nunes \\ Instituto de Geociências - Universidade Estadual de Campinas (UNICAMP) \\ luci@ige.unicamp.br
}

\begin{abstract}
RESUMO
A análise de eventos extremos de precipitação na cidade de Campinas (SP), entre 1976 e 2005, mostrou um aumento no número e no tipo de impactos e um claro padrão socioespacial - os episódios afetaram mais duramente setores menos favorecidos, o que reflete os problemas e riscos advindos da ocupação irregular. Contudo, todo o município registrou algum tipo de ocorrência, mostrando que, mesmo em menor grau, todos os habitantes estão sujeitos a algum grau de risco.
\end{abstract}

Palavras chave: eventos atmosféricos extremos, precipitação, urbanização, mídia.

\title{
RÉSUMÉ
}

L'analyse d'événements extrêmes de précipitations dans la ville de Campinas (SP) entre 1976 et 2005 a montré une augmentation dans le nombre et dans le type d'impact et un précis modèle socio-espacial - les épisodes ont affecté plus durement les secteurs moins favorisés, ce qui reflète les problèmes et risques qui découlent de l'occupation irrégulière. Cependant, toute la ville a enregistré que, même en moindre degré, tous les habitants sont sujets à quelque degré de risque.

Mots-clé: phénomènes météorologiques extrêmes, précipitations, urbanisation, média.

\section{ABSTRACT}

The analysis of the extreme rainfall events in Campinas (SP) from 1976 to 2005, showed an increase in number and type of impacts and a clear socio-spatial pattern - the extreme episodes of rainfall affected more severely the poorest sectors of society, enhancing the problems and risks derived from irregular occupation. Notwithstanding, the whole municipality registered some kind of occurrence, showing that even in lower degree all inhabitants are under some risk.

Key words: extreme atmospheric events, precipitation, urbanization, media.

$1^{*} \mathrm{O}$ texto deste artigo corresponde à comunicação apresentada ao V Encontro Nacional e I Congresso Internacional de Riscos e foi submetido para revisão em 16-06-2009, tendo sido aceite para publicação em 19-02-2010.

Este artigo é parte integrante da Revista Territorium, n. ${ }^{\circ} 17,2010$, @ Riscos, ISBN: 0872- 8941. 


\section{Introdução}

Nos primórdios do século XX, as populações do estado de São Paulo, Brasil, eram essencialmente rurais e, como tal, tinham seus hábitos fortemente marcados pelos ciclos sazonais. Ainda que desde o século XIX existisse conhecimento quanto às variações dos padrões da atmosfera, ele era limitado à esfera científica, restrita a uma parcela bastante diminuta da sociedade. Desse modo, essas questões não faziam parte das preocupações cotidianas da população em geral, até porque as condições da atmosfera eram entendidas pela maioria das pessoas como imutáveis e seguindo um ciclo inabalável e repetitivo.

Tal visão difere da atual: os estados de tempo são largamente discutidos pelas populações, principalmente com o advento da mídia, com suas imagens catastróficas e espetaculares veiculadas em tempo real, e cobrindo os mais distintos locais. Assim, nesse curto espaço de tempo em relação à evolução humana, as questões climáticas adquiriram crescente interesse, principalmente no que diz respeito às peculiaridades do clima urbano que se relacionam as alterações na paisagem natural, com adensamento populacional, alta concentração de construções de alvenaria, utilização de materiais urbanos e substituição de áreas verdes por áreas construídas (Sant' anna Neto, 2002).

No meio urbano, episódios atmosféricos extremos - entendidos como aqueles que se distanciam das condições habituais de uma dada localidade em relação a uma série cronológica - levantam ao mesmo tempo interesse e preocupação, tendo em vista o potencial que apresentam em desestruturar o ambiente físico e as atividades em um determinado lugar, causando inúmeros problemas às comunidades afetadas, sofrimento às populações e acarretando ao poder público vultosos prejuízos. Muitas vezes causadas pela junção da ocorrência de eventos extremos de chuvas e falta de planejamento territorial, as inundações são responsáveis, todos os anos, por milhares de óbitos, além de afetarem cerca de 20 milhões de pessoas em todo o mundo (SMITH, 2004). Dados da Organização das Nações Unidas a respeito dos desastres naturais no ano de 2007 dão conta de que 164 milhões de pessoas no mundo foram afetadas por enchentes.

No Brasil, as inundações respondem por grande parte das mortes por eventos naturais: dados do período de 1900 a outubro de 2008 do EM-DAT (Emergency Events Data Base), atestam que dos 174 desastres registrados no país, 105 referem-se a inundações, que ocasionaram 6.557 vítimas fatais.

Esta questão é particularmente preocupante na região de Campinas (SP), foco deste estudo, uma vez que as inundações são freqüentes, agravadas pela falta de medidas estruturais, como modernização do obsoleto sistema de drenagem municipal, e não-estruturais, como deficiências no planejamento e integração de informações geradas. Tudo isso ocasiona perdas materiais e humanas (YAHN e GIACOMINI, 2002) principalmente em bairros de baixa renda.

\section{Objetivo}

O estudo analisou as frequiências dos eventos extremos diários de precipitação em Campinas entre 1976 e 2005, divididas em três décadas, e os tipos de problemas deflagrados por precipitações intensas nos diferentes setores do município no mesmo período, observando correlação entre o elemento desencadeador e as conseqüências, bem como a evolução no padrão espacial e temporal de suas distribuições.

\section{Caracterização da área de estudo}

Campinas situa-se na porção centro-oeste do estado de São Paulo (fig. 1), estendendo-se por 796,6 km2 e com população de aproximadamente 1.031.887 de habitantes (Instituto Brasileiro de Geografia e Estatística, IBGE, 2007). A cidade é o centro da Região Metropolitana de Campinas (RMC), com mais de 2,3 milhões de habitantes e sede da Região Administrativa de Campinas (RAC), com mais de 5 milhões de habitantes.

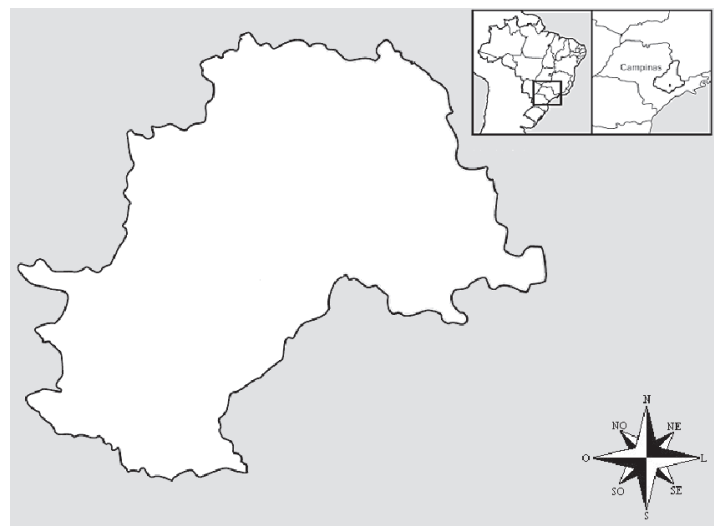

Fig. 1 - Localização da cidade de Campinas. Adaptado de CORTE et. al., 1996

Campinas destaca-se por sua concentração industrial, sendo pólo de ciência e alta tecnologia. Abriga instituições de ensino e pesquisa como o Laboratório Nacional de Luz Sincrotron, o Centro de Pesquisa e Desenvolvimento de Telecomunicações (CpqD), a Empresa Brasileira de Pesquisa Agropecuária (EMBRAPA), o Instituto Agronômico de Campinas (IAC), além de diversas instituições de ensino superior, entre elas a Universidade Estadual de Campinas (UNICAMP) e a Pontifícia Universidade Católica de Campinas (PUCCAMP). 
Em grandes traços, seu clima é tropical subúmido, com verões quentes e úmidos e invernos amenos e com redução de precipitação. Na região onde o município se insere domina na maior parte dos dias do ano a Massa Tropical Atlântica, responsável por condições relativamente estáveis de tempo atmosférico. A Massa Polar atua ao longo de todo o ano, especialmente no inverno, promovendo queda de temperatura e aumento da umidade. O local é sujeito à atuação de uma série de fenômenos, como linhas de instabilidade e entrada de sistemas mais continentalizados, por exemplo. Entre novembro e março configura-se com mais freqüência a ZCAS (Zona de Convergência do Atlântico Sul), que conecta umidade da Amazônia a do Atlântico, e com isso o setor experimenta chuvas mais persistentes e copiosas. A área é também sensível a eventos de $\mathrm{E}$ Niño fortes, que promovem aumento das precipitações, notadamente no outono e inverno (NUNES, 1997 e VICENTE e NUNES, 2005). Os valores médios de temperatura do ar e de precipitações são, respectivamente, $22^{\circ} \mathrm{C}$ e 1.450 $\mathrm{mm} / \mathrm{ano}$, sendo as chuvas concentradas, sobretudo, no semestre primavera-verão, notadamente nos meses de dezembro, janeiro e fevereiro.

A questão populacional é fator importante na dinâmica do município, que ao longo de sua história apresentou incremento demográfico considerável. Segundo Caiado (2002), tal crescimento foi da ordem de 45,7\% entre 1980 e 2000, passando de 664.566 para 968.172 habitantes no período. Concomitantemente, Campinas registrou aumento de pessoas residentes em habitações sub-normais, como coloca o mesmo autor, ao afirmar que a população moradora de sub-habitações, que no ano de 1991 era de $8 \%$, passa para $16,5 \%$ em 2000.

O crescimento demográfico - tanto da população geral quanto da habitante de ocupações irregulares - atrelado à ocupação da terra e à urbanização, ocasiona grandes conseqüências no que diz respeito a inundações e impactos causados por eventos extremos de chuva.

\section{Metodologia}

Os eventos extremos diários de precipitação foram identificados em séries de 5 postos pluviométricos. São eles: o posto do IAC (Instituto Agronômico de Campinas), o da ESALQ (Escola Superior de Agricultura "Luiz de Queiroz", da Universidade de São Paulo) e três postos do DAEE (Departamento de Águas e Energia Elétrica do Estado de São Paulo), a saber, postos Campinas, Fazenda Monte D'Este e Barão Geraldo. A escolha do posto da ESALQ, localizado na cidade de Piracicaba, a aproximadamente $70 \mathrm{~km}$ do município de Campinas, se deu pela relativa proximidade geográfica da cidade foco deste estudo e das semelhantes condições morfológicas entre os dois municípios, além da qualidade das informações apresentadas, uma vez que o posto conta com registros de chuva desde 1917.

Para delimitação de episódios extremos utilizou-se o valor de montante diário igual ou superior a $50 \mathrm{~mm}$, definido como excepcional para a Região Metropolitana de Campinas por VICENTE (2005), pois volumes iguais ou superiores a ele apresentam potencial para deflagrar desestruturações de várias ordens no meio urbano. Esse mesmo montante definido como anômalo foi usado também por CANDIDO (2007) em estudo de inundações em Santa Bárbara D’Oeste, município que faz parte da Região Metropolitana de Campinas, que congrega 19 municípios.

Os eventos foram levantados na Hemeroteca do Centro de Memória da UNICAMP (Universidade Estadual de Campinas), no acervo do jornal Correio Popular, editado na cidade, e na Defesa Civil de Campinas. O período entre 1976 e o fim do primeiro semestre de 1991 foi pesquisado exclusivamente no jornal, já que a Defesa Civil de Campinas, implantada em setembro de 1991, não possui registros de eventos anteriores a essa data.

A análise do trabalho se deu em duas etapas. Na primeira, dividiu-se o período em 3 décadas: de 1976 a 1985, de 1986 a 1995 e de 1996 a 2005. Desta forma, foi possível perceber evolução dos problemas enfrentados pela população de Campinas relacionados aos eventos extremos de chuva. Numa segunda fase, foi analisada a série completa (1976 a 2005), provendo um panorama geral de como os eventos extremos de precipitação afetaram a sociedade campineira.

\section{Critérios adotados na análise dos problemas urbanos}

Alguns critérios foram estabelecidos para a organização e melhor entendimento dos resultados. Os bairros foram divididos em seis classes, de acordo com suas características socioeconômicas: classe alta, médiaalta, média, média-baixa, baixa e favelas. No último tipo, levou-se em consideração bairros que são favelas e/ou que tenham núcleos de favelas. Para tal divisão utilizou-se o Plano Diretor de Campinas (1996), os Planos Locais de Gestão, reportagens de jornal, interpretação visual por meio do programa Google Earth, além de conhecimento pessoal de bairros por parte da primeira autora e conversas com pessoas conhecedoras do município.

As conseqüências encontradas nos eventos selecionados foram separadas em 27 grupos, escolhidos de forma empírica após a coleta de todos. Aparentemente, o número poderia parecer demasiado, mas as especificidades dos episódios levantados revelaram a importância de categorizá-los detalhadamente. Ainda que muitas dessas conseqüências tenham ligação entre 
si, optou-se por separá-las para melhor entendimento e avaliação dos impactos dos episódios extremos de chuva. Seguem abaixo os grupos de ocorrências e suas descrições:

1. Alagamento de imóveis: invasão de água em residências, garagens de prédios, creches, escolas, estabelecimentos comerciais, teatro e centros de saúde. Também se considerou os casos de ocorrência de lama no interior de imóveis;

2. Alagamento de vias: invasão de água em ruas e rodovias. Neste item, levou-se em consideração qualquer menção a bairros ilhados, veículos arrastados ou cobertos pela água, ocorrências de vias com lama ou ruas intransitáveis. Em alguns casos, os dados da Defesa Civil foram fornecidos apenas com a descrição "alagamento". Desta forma, optouse por considerar estes casos referentes ao alagamento de vias somente;

3. Danos em vias: buracos e danos no asfalto e em calçadas, erosão em vias e queda de pontes;

4. Problemas no trânsito: congestionamentos causados pela chuva, trânsito desviado, pane em semáforos e falta ou atraso nos transportes públicos;

5. Deslizamentos de terra: referentes à queda de barrancos e soterramentos;

6. Risco de deslizamento: locais em que há o risco iminente de deslizamento de terra;

7. Desabamento total ou parcial de imóveis: queda de muros, paredes ou desabamento total. Neste item não se levou em consideração a razão do desabamento, podendo ser proveniente de soterramentos ou da força da água;

8. Risco de desabamento: residências, igrejas, escolas, creches, pontes, postes, muros e paredes com risco de desabamento. Casos de imóveis interditados com rachaduras, infiltrações e estruturas abaladas igualmente foram considerados neste item;

9. Falta de energia: bairros que sofreram temporariamente corte de energia, incluindo danos em transformadores e curto-circuito;

10. Queda de árvores: árvores caídas e/ou arrancadas;
11. Árvores com risco: árvores comprometidas, com risco de queda;

12. Desabrigados: pessoas retiradas, removidas, transferidas e obrigadas a deixarem suas casas, por razões diversas;

13. Danos no sistema telefônico: bairros com pane em sistemas telefônicos;

14. Risco de alagamento: locais em que há risco de haver alagamentos;

15. Destelhamento de imóveis: engloba destelhamento de residências, estabelecimentos comerciais, escolas e centros de saúde;

16. Abastecimento de água prejudicado: falta de água, rompimento de adutoras e destruição de encanamentos de água;

17. Problemas na rede de esgoto: entupimento da rede e conseqüente retorno de esgoto pelos ralos de casas;

18. Queda de fios: queda de fios de eletricidade;

19. Queda de postes: postes que caíram ou tombaram;

20. Acidentes: referente a acidentes de carro, em ruas ou rodovias;

21. Feridos: pessoas que se feriram em acidentes de carro, desabamento total ou parcial de imóveis ou queda de raio;

22. Mortos: vítimas fatais em acidentes de carro, afogamento ou desabamento de imóveis;

23. Desaparecidos: pessoas não encontradas após o advento de alguma ocorrência (grande parte como conseqüência da força da água);

24. Alagamento de parque: invasão de parques por parte da água;

25. Queda de outdoor: queda de painéis de propaganda;

26. Queda de raio: relacionado a tempestades elétricas;

27. Rompimento de represa: como o nome já diz.

Para a interpretação dos grupos de impactos, levou-se em conta apenas os bairros que apresentaram duas ou mais 
ocorrências durante todo o período analisado; no caso de grupos de eventos em que houve apenas uma ocorrência por bairro, esse caso foi levado em consideração.

$\mathrm{Na}$ análise das notícias de jornais os impactos das chuvas foram reportados de acordo com seus locais de ocorrência, que ocorreram em rodovias, avenidas ou ruas, sem menção aos bairros em que se localizam. Com o intuito de saber em quais bairros e, conseqüentemente, regiões do município tais vias se encontram, utilizou-se o site dos Correios. No caso de ruas, avenidas ou rodovias que passam por mais de um bairro, considerou-se aquele que tem a maior parte das vias em questão passando em seus limites - como exemplo, no caso da Avenida José de Souza Campos, que corta os bairros Nova Campinas, Cambuí, Centro e Chácara da Barra, considerou-se o primeiro dos bairros, uma vez que constava duas vezes na listagem dos Correios. Em algumas situações, não houve maioria em relação aos bairros, fazendo com que se considerassem todos os listados, ainda que o número de ocorrências possa ter sido superestimado.

Ainda que a organização dos dados tenha sido feita de acordo com os bairros atingidos, levou-se em consideração, no caso do mapeamento, a divisão em regiões utilizada pela Defesa Civil de Campinas, em Sul, Leste, Norte, Noroeste e Sudoeste (fig. 2). É importante ressaltar que a divisão em questão não condiz com a utilizada nos Planos Diretores de Campinas, em macrozonas.

\section{Síntese e análise dos resultados}

Em 360 dias (3\% do período analisado) foram registrados montantes pluviais iguais ou acima de $50 \mathrm{~mm}$. Esses eventos extremos de chuva ocorreram, em grande parte, no verão e primavera: 188 e 110 eventos, respectivamente.

Ao longo dos 30 anos analisados não houve qualquer tendência na incidência desses episódios anomalamente elevados (fig. 3). Destaca-se que o ano de 1983 - o que apresentou mais registros de episódios excepcionais - foi um ano de ocorrência do fenômeno El Niño, que influenciou os volumes precipitados em todo o estado de São Paulo (Nunes, 1997; Vicente e Nunes, 2005). Todavia, em alguns eventos de El Niño a Corrente do Jato é deslocada de sua posição original, e com isso ocorre bloqueio das massas extratropicais, que ficam restritas ao sul do Brasil, norte da Argentina, Uruguai e sul do Paraguai, que com isso experimentam intensa precipitação, diferentemente do estado de São Paulo. Isso ocorreu no El Niño de 1997-1998, de modo que nesse período houve poucos eventos extremos e baixos volumes de precipitação (NunEs, 2007).

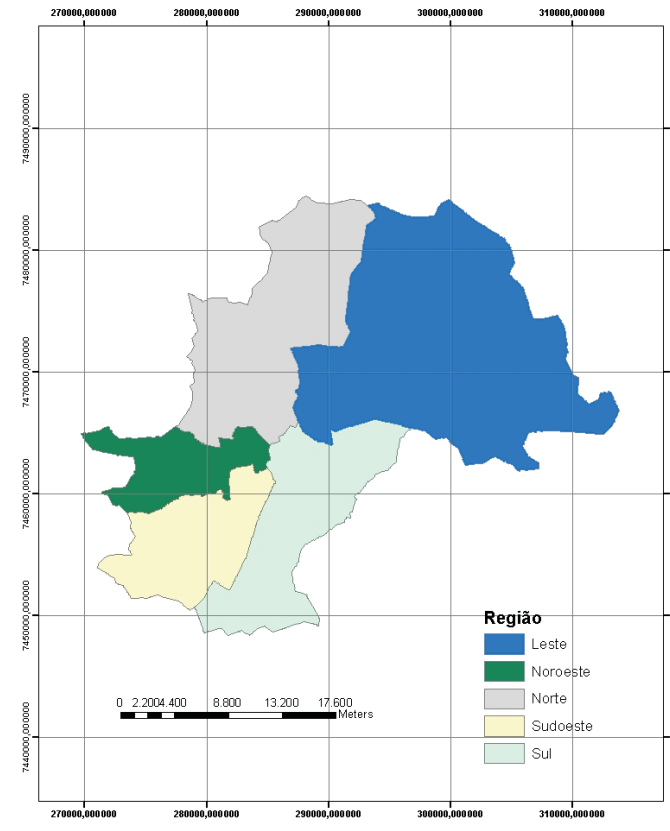

Fig. 2 - Divisão de Campinas utilizada pela Defesa Civil do município.

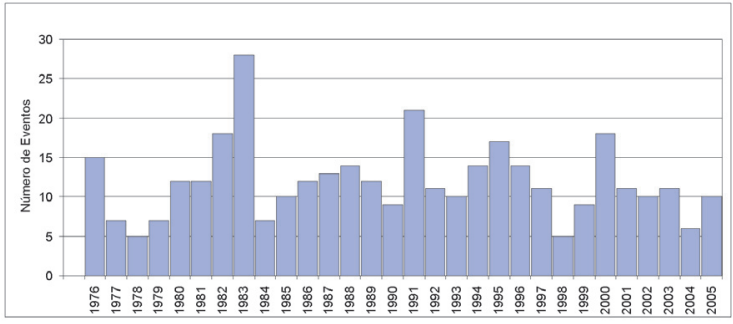

Fig. 3 - Número de eventos extremos de chuva por ano em Campinas entre 1976 e 2005.

Nas pesquisas efetuadas em jornal ou em dados da Defesa Civil, não foi encontrado registro das conseqüências de 145 eventos extremos (40,3\% do total). Tendo em vista que grande parte das falhas está nos primeiros 18 anos (139 eventos), algumas hipóteses podem ser aventadas:

- A primeira delas diz respeito à fonte de dados utilizada: a Defesa Civil se consolida na metade do ano de 1991, de modo que fatos anteriores não constam no registro desse órgão. Já o jornal Correio Popular aparece como fonte exclusiva de dados desta pesquisa entre os anos de 1976 e 1991, sendo que nos anos da década de 1970 analisados e no começo da década de 1980 a configuração e tipos de reportagens tinham características diferentes das observadas atualmente: em determinadas épocas do ano, as notícias de chuvas não ganhavam destaque, uma vez que o jornal priorizava outras informações, como 
a cobertura do carnaval em fevereiro e das eleições em outubro.

- A segunda, leva em conta que em alguns desses dias o total pluviométrico ficou muito próximo aos $50 \mathrm{~mm} / 24 \mathrm{~h}$., podendo não ter apresentado quantidade de chuva suficiente para deflagrar prejuízos no meio urbano. Como estes danos se dão, principalmente, em áreas ocupadas por populações de menor poder aquisitivo, residentes de bairros de baixa renda e com pouca infra-estrutura, pode-se inferir que chuvas acima de $50 \mathrm{~mm} / 24 \mathrm{~h}$. teriam menor potencial para deflagrar problemas no começo do período analisado, já que a população moradora de sub-habitações era menor há 30 anos.

Análise da década 1: 1976-1985

A primeira década analisada, referente aos anos entre 1976 e 1985, apresentou menor número de impactos. As três principais ocorrências referem-se a alagamento de vias, problemas no trânsito e alagamento de imóveis (Quadro I).

Essa década não apresentou registros relacionados à queda de postes, de fios, desaparecidos, risco de deslizamento e alagamento, árvores com risco de queda, alagamento de parques, queda de raios, rompimento de represas, queda de outdoors e problemas na rede de esgoto. Nota-se, ainda, que alguns tipos de impactos apresentaram claramente um padrão socioespacial. Os que afetaram de maneira mais intensa os bairros populares (bairros de classe baixa, média-baixa e favelas), foram: alagamento de imóveis, danos em vias, problemas no

QUADRo I - Tipos de impactos e número de ocorrências e de bairros atingidos de 1976 a 1985.

\begin{tabular}{|c|c|c|c|}
\hline No. de ocorrências & Porcentagem & $\begin{array}{c}\text { No. de Bairros } \\
\text { afetados }\end{array}$ & Impactos \\
\hline 60 & 28,2 & 31 & Alagamento de Vias \\
\hline 43 & 20,2 & 27 & Problemas no trânsito \\
\hline 26 & 12,2 & 19 & Alagamento de Imóveis \\
\hline 25 & 11,7 & 24 & Danos em vias \\
\hline 9 & 4,2 & 8 & Queda de árvores \\
\hline 7 & 3,3 & 6 & Abastecimento de água prejudicado \\
\hline 7 & 3,3 & 7 & Risco de desabamento \\
\hline 7 & 3,3 & 4 & Desabamento total ou parcial de imóveis \\
\hline 6 & 2,8 & 2 & Acidentes \\
\hline 6 & 2,8 & 6 & Desabrigados \\
\hline 5 & 2,4 & 3 & Feridos \\
\hline 5 & 2,4 & 5 & Danos no sistema telefônico \\
\hline 2 & 0,9 & 2 & Imóveis Destelhados \\
\hline 2 & 0,9 & 2 & Mortos \\
\hline 2 & 0,9 & 2 & Deslizamento de terra \\
\hline 1 & 0,5 & 1 & Falta de energia \\
\hline 213 & 100,0 & & \\
\hline
\end{tabular}

trânsito, feridos, mortos, danos no sistema telefônico, problemas no abastecimento de água, deslizamento de terra, desabrigados, destelhamento e desabamento total ou parcial de imóveis. No caso dos bairros de classes média, média-alta e alta, os alagamentos de vias foram os fenômenos mais recorrentes.

A figura 4 apresenta as ocorrências deflagradas por chuvas. Seu exame permite aferir os setores de Campinas mais afetados:

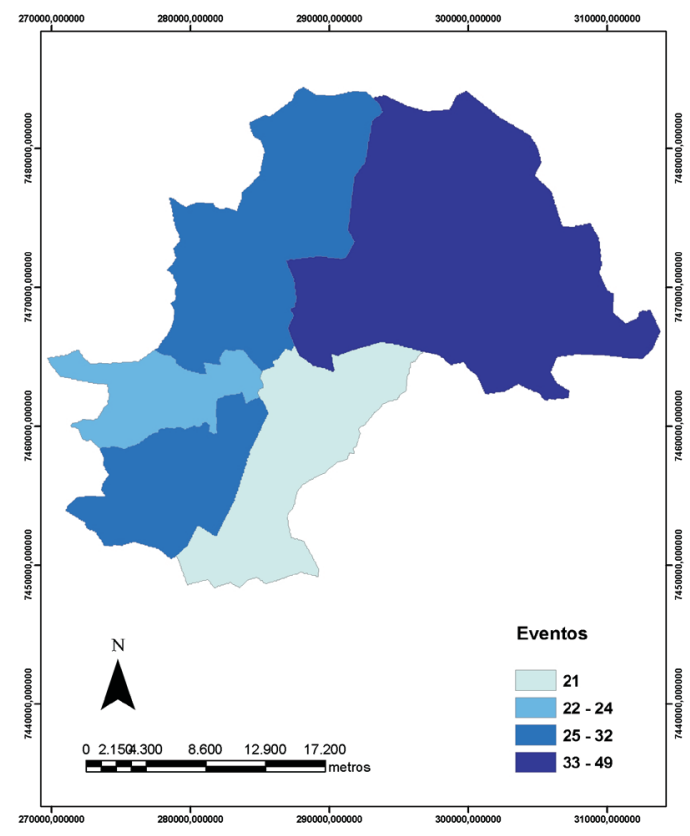

Fig. 4 - Número de ocorrências de acordo com região entre 1976 e 1985.

A maior parte dos impactos no meio urbano aconteceu na região leste (49 registros), seguida das regiões norte e sudoeste, que apresentaram a mesma quantidade de ocorrências ( 32 em cada região) e noroeste e sul, com 24 e 21 registros, respectivamente.

\section{Análise da década 2: 1986-1995}

As três principais ocorrências observadas nesse período referem-se a alagamento de imóveis, de vias e risco de desabamento (Quadro II).

Nessa década não houve ocorrência relacionada à queda de raios, rompimento de represas, queda de outdoors e alagamento de parques.

O padrão socioespacial dos impactos é claro, uma vez que, dos 23 tipos observados, 16 ocorreram em bairros populares. Foram eles: alagamento de imóveis, feridos, mortos, desaparecidos, deslizamento de terra, risco de deslizamento de terra, desabrigados, destelhamentos, problema no abastecimento de água, entupimento de redes de esgoto, problemas no sistema telefônico, 
Quadro II - Tipos de impactos, número de ocorrências e de bairros atingidos de 1986 a 1995.

\begin{tabular}{|r|r|r|c|}
\hline No. de ocorrências & Porcentagem & \multicolumn{1}{c|}{$\begin{array}{c}\text { No. de bairros } \\
\text { afetados }\end{array}$} & Impactos \\
\hline 256 & 23,7 & 124 & Alagamento de imóveis \\
\hline 159 & 14,7 & 73 & Alagamento de vias \\
\hline 158 & 14,6 & 88 & Risco de desabamento \\
\hline 85 & 7,9 & 51 & Queda de árvores \\
\hline 78 & 7,2 & 47 & Desabamento total ou parcial de imóveis \\
\hline 69 & 6,4 & 47 & Danos em vias \\
\hline 67 & 6,2 & 44 & Problemas no trânsito \\
\hline 51 & 4,7 & 44 & Falta de energia \\
\hline 39 & 3,6 & 34 & Deslizamento de terra \\
\hline 37 & 3,4 & 37 & Abastecimento de água prejudicado \\
\hline 20 & 1,8 & 16 & Desabrigados \\
\hline 13 & 1,2 & 12 & Destelhamento de imóveis \\
\hline 8 & 0,7 & 7 & Árvores com risco \\
\hline 7 & 0,7 & 4 & Feridos \\
\hline 6 & 0,6 & 6 & Mortos \\
\hline 6 & 0,6 & 2 & Acidentes \\
\hline 5 & 0,5 & 5 & Queda de fios \\
\hline 5 & 0,5 & 5 & Risco de deslizamento \\
\hline 4 & 0,4 & 4 & Risco de alagamento \\
\hline 2 & 0,2 & 2 & Desaparecidos \\
\hline 2 & 0,2 & 2 & Queda de poste \\
\hline 2 & 0,2 & 2 & Entupimento da rede de esgoto \\
\hline 1 & 0,1 & 1 & Danos no sistema telefônico \\
\hline 1080 & 100,0 & & \\
\hline & & & \\
\hline & & & \\
\hline & & &
\end{tabular}

desabamento total ou parcial de imóveis, risco de desabamento, acidentes de carro, queda de fios e de postes.

As consequiências que tiveram maior incidência nos bairros não populares foram: alagamentos e danos em vias, problemas no trânsito, falta de energia, queda de árvores e árvores com risco de queda.

A espacialização das ocorrências mostra que a região sul foi a mais afetada, seguida da região leste, sudoeste, norte e noroeste (fig. 5):

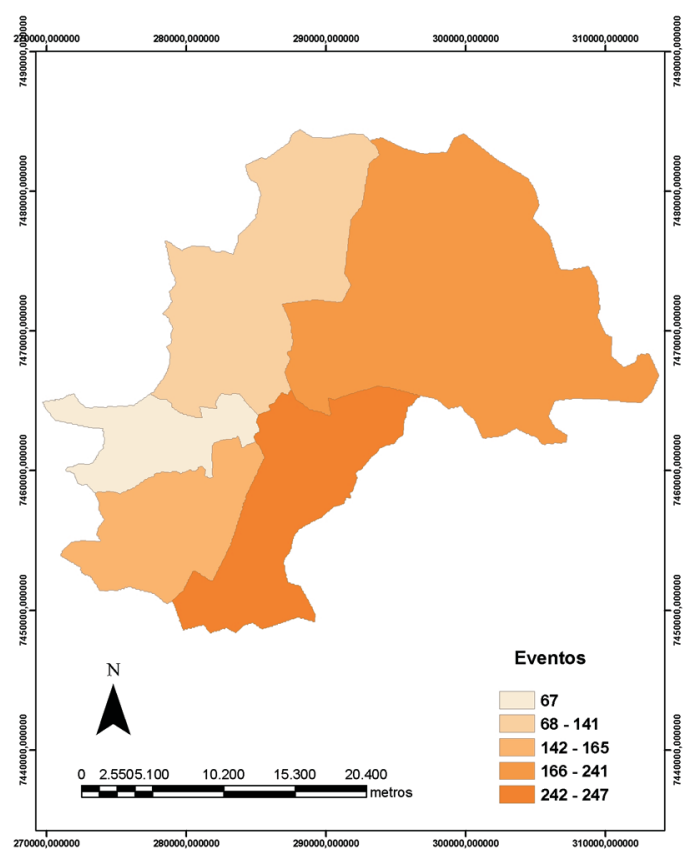

Fig. 5 - Número de ocorrências de acordo com região entre 1986 e 1995.
Análise da década 3: 1996-2005

Das três décadas analisadas, essa foi a que registrou maior número de ocorrências. Os três principais tipos foram: alagamento de imóveis, risco de desabamento e alagamento de vias (Quadro III).

QUADRO III - Tipos de impactos, número de ocorrências e de bairros atingidos de 1996 a 2005.

\begin{tabular}{|c|c|c|c|}
\hline No. de ocorrências & Porcentagem & $\begin{array}{l}\text { No. de bairros } \\
\text { afetados }\end{array}$ & Impactos \\
\hline 567 & 24,4 & 199 & Alagamento de imóveis \\
\hline 430 & 18,5 & 172 & Risco de desabamento \\
\hline 265 & 11,5 & 107 & Alagamento de vias \\
\hline 210 & 9,1 & 95 & Queda de árvores \\
\hline 172 & 7,4 & 119 & Desabamento \\
\hline 152 & 6,6 & 93 & Deslizamento \\
\hline 107 & 4,6 & 52 & Falta de energia \\
\hline 97 & 4,2 & 36 & Problemas no trânsito \\
\hline 86 & 3,7 & 57 & Danos em vias \\
\hline 51 & 2,2 & 34 & Árvores com risco \\
\hline 44 & 1,9 & 28 & Desabrigados \\
\hline 40 & 1,7 & 33 & Risco de deslizamento \\
\hline 29 & 1,3 & 22 & Destelhamento \\
\hline 17 & 0,7 & 16 & Feridos \\
\hline 17 & 0,7 & 14 & Risco de alagamento \\
\hline 10 & 0,4 & 9 & Acidentes \\
\hline 6 & 0,3 & 6 & Mortos \\
\hline 4 & 0,1 & 4 & Queda de fios \\
\hline 3 & 0,1 & 3 & Desaparecidos \\
\hline 3 & 0,1 & 3 & Abastecimento de água \\
\hline 2 & 0,1 & 2 & Danos no sistema telefônico \\
\hline 2 & 0,1 & 2 & Alagamento de parques \\
\hline 2 & 0,1 & 2 & Problemas no esgoto \\
\hline 1 & 0,0 & 1 & Queda de poste \\
\hline 1 & 0,0 & 1 & Queda de outdoors \\
\hline 1 & 0,0 & 1 & Queda de raio \\
\hline 1 & 0,0 & 1 & Rompimento de represa \\
\hline 2320 & 100,0 & & \\
\hline
\end{tabular}

O período registrou todos os tipos de ocorrências descritos no item "Critérios estabelecidos".

A quantidade de impactos que atingiu os bairros da cidade apresenta, assim como nas décadas anteriores, mais ocorrências em bairros populares, especialmente: alagamento de imóveis, problemas no trânsito, feridos, mortos, desaparecidos, deslizamento de terra, risco de deslizamento de terra, desabrigados, destelhamento, desabamento total ou parcial de imóveis, risco de desabamento, acidentes de carro, queda de postes, alagamento de parques, queda de raio e rompimento de represa.

Ainda que os bairros não populares tenham tido menos episódios, neles foram registrados alagamento e danos em vias, falta de energia, queda de árvores e risco de queda de árvores.

A espacialização de tais eventos e as regiões mais atingidas (leste e sul) pode ser vista na Figura 6:

Análise do período completo (1976-2005)

A observação das três décadas forneceu um panorama de como os eventos extremos de chuva impactaram o meio urbano na cidade de Campinas, demonstrando que 


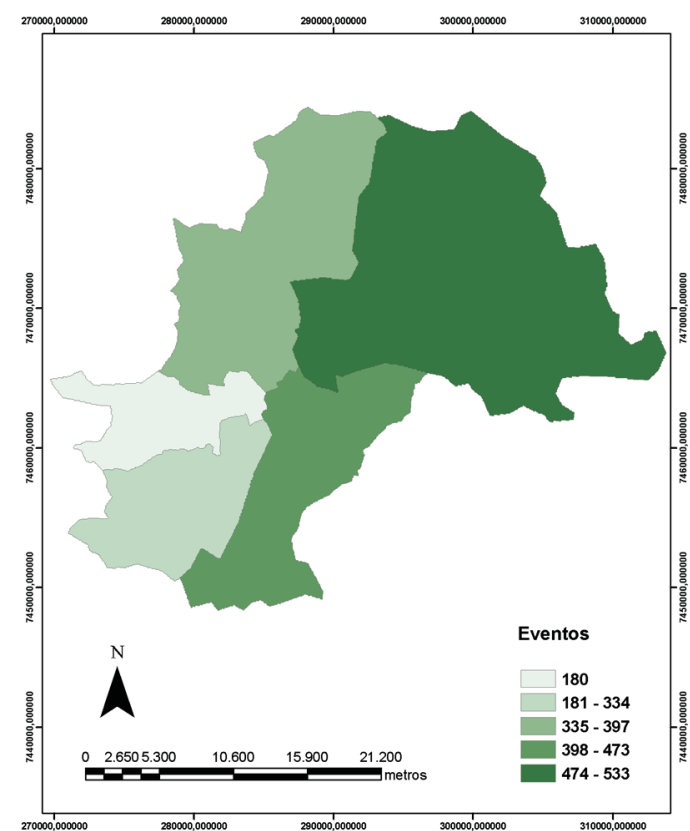

Fig. 6 - Número de ocorrências de acordo com região entre 1996 e 2005.

as principais ocorrências foram alagamento de imóveis, risco de desabamento e alagamento de vias (QUADRo IV):

O maior número de casos foi de alagamento de imóveis, que a partir da segunda década analisada se constituiu no problema mais comum deflagrado por chuvas em Campinas, com ocorrências em bairros de todos os estratos sociais.

Alagamentos de vias contabilizaram transtornos em 79 bairros. Ainda que os populares sejam maioria (somando 50 ), os 8 que apresentaram maior número de ocorrências

QuADRo IV - Tipos de impactos, número de ocorrências e de bairros atingidos de 1976 a 2005.

\begin{tabular}{|c|c|c|c|}
\hline No. de ocorrências & Porcentagem & $\begin{array}{l}\text { No. de bairros } \\
\text { afetados }\end{array}$ & Impactos \\
\hline 849 & 23,5 & 233 & Alagamento de imóveis \\
\hline 595 & 16,5 & 190 & Risco de desabamento \\
\hline 484 & 13,4 & 146 & Alagamento de vias \\
\hline 304 & 8,4 & 107 & Queda de árvores \\
\hline 257 & 7,1 & 136 & Desabamento \\
\hline 207 & 5,7 & 77 & Problemas no Trânsito \\
\hline 193 & 5,3 & 108 & Deslizamento \\
\hline 180 & 5,0 & 91 & Danos em vias \\
\hline 159 & 4,4 & 74 & Falta de energia \\
\hline 70 & 1,9 & 41 & Desabrigados \\
\hline 59 & 1,6 & 38 & Árvores com risco de queda \\
\hline 47 & 1,3 & 43 & Abastecimento de água \\
\hline 45 & 1,3 & 36 & Risco de deslizamento \\
\hline 44 & 1,2 & 32 & Destelhamento \\
\hline 29 & 0,8 & 21 & Feridos \\
\hline 22 & 0,6 & 12 & Acidentes \\
\hline 21 & 0,6 & 18 & Risco de alagamento \\
\hline 14 & 0,4 & 13 & Mortos \\
\hline 9 & 0,3 & 9 & Queda de fios \\
\hline 8 & 0,2 & 8 & Danos no sistema telefônico \\
\hline 5 & 0,1 & 4 & Desaparecidos \\
\hline 4 & 0,1 & 4 & Problemas na rede de esgoto \\
\hline 3 & 0,1 & 3 & Queda de poste \\
\hline 2 & 0,1 & 2 & Alagamento de parque \\
\hline 1 & 0,0 & 1 & Queda de outdoor \\
\hline 1 & 0,0 & 1 & Queda de raio \\
\hline 1 & 0,0 & 1 & Rompimento de represa \\
\hline 3613 & 100,0 & & \\
\hline
\end{tabular}

correspondem a bairros de classe média, média-alta e alta.

Dos 34 bairros atingidos por danos em vias, 15 são favelas, 3 são bairros de renda baixa e 2 de renda médiabaixa. Assim como no caso de alagamento de vias, os bairros com maior número de episódios são referentes àqueles com grande fluxo de veículos.

A tendência se mantém no caso de problemas no trânsito. Dos 39 bairros atingidos, 17 são favelas e 3 bairros de classe baixa. 0 restante corresponde a bairros de classe média, média-alta e alta, incluindo os cinco bairros com maior número de ocorrências.

Grande parte dos bairros que registraram feridos, mortos e desaparecidos corresponde aos de classes mais baixas. Foram 6 os bairros onde houve feridos, 5 deles, favelas. No caso de mortos, apenas um bairro, que tem núcleo de favela, apresentou registros, com 2 ocorrências. Da mesma forma, no caso de desaparecidos, apenas uma favela apresentou 2 ocorrências.

Os bairros atingidos por quedas de árvores somaram 58 , sendo 13 favelas, 10 bairros de classe baixa e 6 bairros de classe média-baixa. Enfatiza-se que para esse tipo de registro os bairros com maior número de eventos não foram os de classes mais baixas. Igual tendência se percebe no caso de árvores com risco de queda: foram 14 bairros atingidos e apenas 3 referentes a classes mais baixas. 0 restante corresponde a bairros de classe alta, média-alta e média. Tal aspecto sublinha o fato de haver maior arborização em bairros de padrão mais alto, o que se relaciona a melhor conforto térmico (maior umidade e sombreamento).

Avaliando os 42 bairros onde houve deslizamentos de terra e risco de deslizamento, percebe-se haver nítido padrão socioespacial: 21 favelas, 9 bairros de classe baixa e 2 bairros de classe média-baixa. No caso de risco de deslizamento, todos os bairros selecionados (em um total de 6) são favelas.

No tocante ao desabamento total ou parcial de imóveis, 33 bairros dos 51 selecionados correspondem à população de classe baixa: foram 21 favelas, 7 bairros de classe baixa e 5 bairros de classe média-baixa. Igual tendência é percebida quanto ao risco de desabamento de imóveis, em que 119 bairros foram selecionados, dentre os quais 45 são favelas, 28 bairros de classe baixa e 6 bairros de classe média-baixa.

Os bairros onde ocorreram casos de desabrigados foram 12 , sendo que 8 são favelas e 2 bairros de classe baixa.

Imóveis destelhados ocorreram em 7 bairros, sendo 5 deles favelas e um bairro de classe baixa.

Acidentes ocorreram em 3 favelas próximas a grandes rodovias, como a Via Anhangüera (que interliga Campinas 
a São Paulo) e Rodovia D. Pedro (que conecta Campinas ao Vale do Paraíba, e de lá ao Rio de Janeiro e norte do país).

Quedas de fios e de postes apresentaram, também, um padrão socioespacial, uma vez que no primeiro caso 4 favelas, um bairro de classe baixa e outro de classe média-baixa sofreram com o problema, dentre os 9 bairros que apresentaram registros. Já no caso de queda de postes, 3 bairros foram atingidos, sendo 2 deles favelas.

Problemas no abastecimento de água e na rede de esgoto igualmente tiveram padrões socioespaciais, uma vez que, dos 3 bairros afetados no primeiro caso, um deles refere-se a favela e outro a bairro de classe médiabaixa. No segundo caso, dos 4 bairros selecionados, 2 são favelas e um referente a bairro de classe média.

A falta de energia atingiu 35 bairros, sendo 12 deles favelas e 3 bairros de classe baixa. Nesse caso há predomínio de bairros de classe média, média-alta e alta, estando neste grupo os 7 bairros com maior número de ocorrências.

Danos no sistema telefônico atingiram 8 bairros, sendo 5 de classe baixa.

Os casos de queda de outdoor, queda de raio, alagamento de parques e rompimento de represa, foram iguais aos casos da última década analisada (1996 a 2005).

Foram 3 os bairros que apresentaram locais com risco de alagamento: um deles favela, um de classe baixa e outro de classe média.

A espacialização dos eventos nas 3 décadas analisadas pode ser vista na Figura 7, com destaque para as regiões sul e leste, que apresentaram o maior número de ocorrências registradas.

\section{Conclusões}

O levantamento e análise das informações permitiram tecer algumas considerações a respeito do padrão socioespacial e da evolução, em número e tipo, dos impactos ocasionados por eventos extremos de chuva em Campinas.

A avaliação mostra ter havido um aumento no número de tipos, incidências e bairros atingidos ao longo do tempo. Dessa maneira, a primeira década apresentou menos tipos de impactos em relação às outras duas décadas: não há registro de queda de outdoors, postes, fios, casos de desaparecidos, risco de deslizamento e alagamento, queda de raios, rompimento de represas, árvores com risco de queda e problemas na rede de esgoto. A segunda década foi intermediária, apresentando mais ocorrências e tipos do que a primeira, porém menos

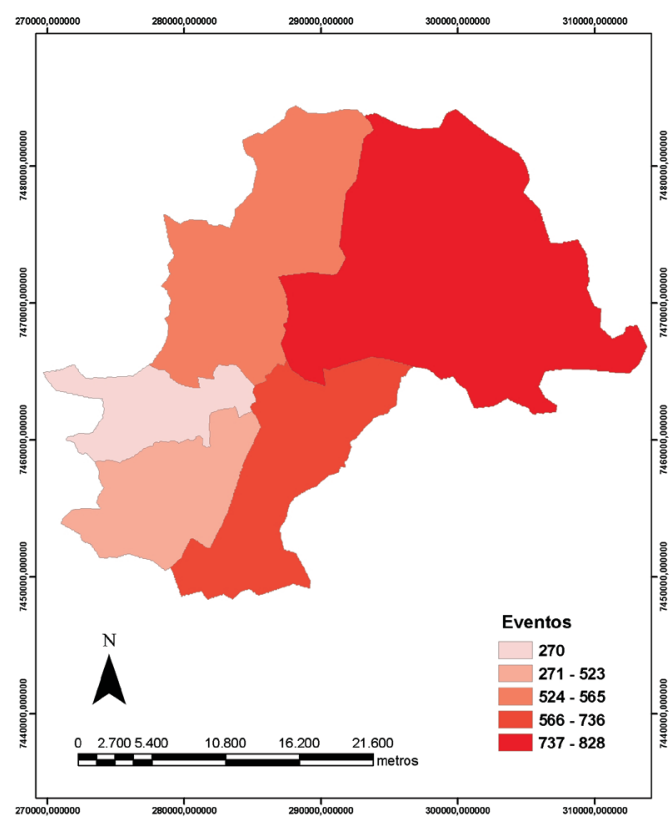

Fig. 7 - Número de ocorrências de acordo com região entre 1976 e 2005.

tipos de consequiências e número de casos em relação à terceira década, não tendo havido registros de raios, alagamento de parques, rompimento de represa e queda de outdoors.

Tal tendência também é notada ao se analisar os dados de cada período: a primeira década apresentou 213 ocorrências, a segunda, 1.080 , e a terceira, 2.320 registros, incrementos decenais bastante substanciais, muito superiores ao crescimento populacional da cidade em iguais períodos.

É relevante salientar que houve aumento no número e tipo de impactos; contudo, a quantidade de eventos extremos de chuva que deflagram tais ocorrências calamitosas não aumentou no mesmo período. Tal acontecimento se deve, provavelmente, a dois fatores: 0 primeiro deles refere-se às fontes de pesquisa, uma vez que a primeira década foi exclusivamente analisada por meio de jornais o que, conforme previamente alertado, pode interferir na quantidade das informações. Não obstante, como houve aumento de eventos de forma bastante significativa entre a segunda e a terceira décadas, quando as fontes de dados consultados foram as mesmas, esse fator teria uma influência parcial na tendência dessa primeira década. 0 segundo fator corresponde ao aumento populacional, notadamente no contingente de população de baixa renda, uma vez que este grupo social é mais correntemente e duramente afetado no caso de impactos promovidos por chuva, principalmente por ocuparem áreas de risco.

A análise das informações registradas permitiu perceber que o padrão socioespacial se mantém, pois os bairros populares atingidos são maioria em grande parte dos 
tipos de impactos observados. Os casos que fugiram a este padrão foram: alagamento de vias, problemas no trânsito (em ambos os casos, bairros de classe média, médiaalta e alta apresentaram quantidade de ocorrências muito superior aos bairros de classes populares), queda de árvores, danos em vias, falta de energia, danos no sistema telefônico, abastecimento de água prejudicado, problemas na rede de esgoto, risco de queda de árvores, queda de fios e queda de postes. Tais impactos afetam mais freqüentemente populações de renda mais alta e raramente são relacionados a tragédias, causando apenas transtornos leves à população, sem afetar suas integridades físicas.

A respeito da espacialização dos dados, a região leste destacou-se por apresentar maior número de eventos nos casos da primeira e da terceira décadas e por ser a segunda região que concentrou maior número de eventos no caso da segunda década. A hipótese levantada a respeito de tal fato leva em conta a concentração populacional da região que, de acordo com o Plano Diretor de Campinas (1996), é a mais adensada do município.

Este estudo evidencia que os fenômenos atmosféricos extremos deflagram sérios problemas no meio urbano, afetando mais forte e rotineiramente os grupos sociais menos favorecidos economicamente, que se instalam em locais de menor valor imobiliário e maior grau de risco. Mas chama a atenção o fato de que muitos bairros de Campinas, independente do extrato social, registraram algum tipo de ocorrência, mostrando que praticamente toda a população está exposta a risco, ainda que de diferente natureza, o que se coloca como um aspecto de grande relevância a ser considerado pelo poder público.

\section{Referências bibliográficas}

CAnDIDO, Daniel Henrique (2007) - Inundações no município de Santa Bárbara d'Oeste, SP: condicionantes $e$ impactos. Instituto de Geociências, Universidade Estadual de Campinas, Campinas, Dissertação de Mestrado, 235 p.. Disponível em: <http://libdigi.unicamp.br/ document/?code=vtls000417099>

CaIAdo, Aurílio S. C et al (2002) - "Município de Campinas". In: Cano, Wilson; Brandão, Carlos. A. (coord.), A Região Metropolitana de Campinas: Urbanização, Economia, Finanças e Meio Ambiente, Editora da Unicamp, Campinas; p. 95-188.

CoRTE, A. A. et. al. (1996) - "Aspectos eco-epidemiológicos da leishmaniose tegumentar americana no município de Campinas”. Cadernos de Saúde Pública, vol. 12, n.4, Rio de Janeiro. Out/Dez. 1996.
NunEs, Lucí Hidalgo (1997) - Distribuição espaçotemporal da pluviosidade no estado de São Paulo: tendências, variabilidade, processos intervenientes. Escola Politécnica Universidade de São Paulo, São Paulo, Tese de Doutoramento, $197 \mathrm{p}$.

Prefeitura Municipal de Campinas (1996) - Plano Diretor de Campinas. SEPLAMA - Secretaria de Planejamento e Meio Ambiente.

Sant ' anna Neto, João Lima (2002) - Os Climas das Cidades Brasileiras. Universidade Estadual de São Paulo, Presidente Prudente, $227 \mathrm{p}$.

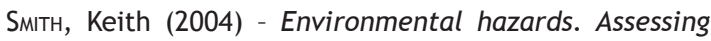
risk \& reducing disaster. Routledge, London, $306 \mathrm{p}$.

VICENTE, Andrea Koga (2005) - Eventos extremos de precipitação na Região Metropolitana de Campinas. Universidade Estadual de Campinas, Campinas, Dissertação de Mestrado, 160 p.

Disponível em http://libdigi.unicamp.br/ document $/$ ?code $=v t l s 000346675$

ViCente, Andrea Koga; Nunes, Lucí Hidalgo (2005) "A influência do El Nino Oscilação Sul na precipitação da Região Metropolitana de Campinas - SP". In: XI Simpósio Brasileiro de Geografia Física Aplicada - Geografia, tecnociência, sociedade e natureza, São Paulo. CD do XI Simpósio Brasileiro de Geografia Física Aplicada - Geografia, tecnociência, sociedade e natureza. São Paulo, p.1192-1200.

YAHN, Armando Gallo; GIACOMINI, Adriana A.R.V. Isenburg (2002) - "Recursos Hídricos e Saneamento". In: FonseCA, Rinaldo Barcia; Davanzo, Áurea M.Q.; Negreiros, Rovena M.C. (orgs.), Livro Verde: Desafios para a gestão da Região Metropolitana de Campinas, Unicamp - IE, Campinas, p. 195-223.

\section{Sítios especializados}

CoRrelos <www.correios.com.br > (acessado em outubro de 2007)

EM-DAT - Emergency Disasters Data Base <www.emdat. be> (acessado em setembro de 2008)

IBGE - Instituto Brasileiro de Geografia e Estatística $<$ www.ibge.gov.br> (acessado em fevereiro de 2007) 